\title{
Using Twitter for Branding: Hotel Strategies in Kenya
}

\author{
Patrick Owoche $^{1}$, Samuel Mbugua $^{2}$, Anselemo Ikoha ${ }^{3}$ \\ Tutorial Fellow, Department of Information Technology, Kibabii University, Bungoma, Kenya ${ }^{1}$ \\ Senior Lecturer, Department of Information Technology, Kibabii University, Bungoma, Kenya ${ }^{2,3}$
}

\begin{abstract}
Globalization, mobile computing and changes in consumer behaviour are aspects brought about by the new developments in IT that are changing the way business organizations conduct their business. Branding in travel and tourism industry is no exception and the practitioners must consider social media in their online branding strategies. This paper examines the extent to which the hotel industry uses Twitter social networking site in their branding strategies. The study used media content analysis to investigate 35 star rated hotels Twitter account in Kenya. Twitter posts timing, content type and engagement metrics were analysed. The results indicate that the timing of tweets and the Twitter post media type have a bearing on the rate of engagement. On the practical side, this study shades light on how Twitter is utilized by hotels for branding purposes and creates recommendations on how hotels can optimize customer engagement with their tweets. The study also enriches literature in the use of Twitter as a branding tool.
\end{abstract}

Keywords: Twitter engagement, social media in hotels, Social media branding, Twitter posting, timing of tweets

\section{INTRODUCTION}

The recent developments in IT as a whole and the Web in particular comes with mixed fortune for hotel industry. On the positive side, IT enables the industry to achieve operational excellency, provide insights for decision making and enable hotels that align the business objectives with technology to gain competitive edge as well as creating a platform for hotels to intimately relate with their customers. These developments also come with challenges to the industry. For instance, customers are more empowered, competition accelerated and personalized customer satisfaction.

Digital era is also accompanied by changes in customers' behaviour. Zmuda [1] posits that the new supercharged customer is more curious, more demanding, and more impatient than ever before. It has created smart customers who wants to be dealt with as an individual. According to research conducted by Salesforce [2], 58\% of consumers admit that technology has significantly changed their expectations of how companies should interact with them. The smart hotel guests do background checks, and purchase wherever they are and whenever they want. The guests of today expect hotels to understand their changing preferences, otherwise they simply switch brands which is just a click away. According to Salesforce [2], 70\% of consumers agree that technology has made it easier than ever before to take their business elsewhere. With information-savvy guests controlling the marketplace, hotels are in dire need of branding platforms that will enable them engage with the customers and also get information not just about their preferences but also their behaviour. Customers want one-on-one personalized engagement at every touchpoint in the digital and physical worlds [3]. One way of achieving this is through customer engagement. In response to the advancement in IT, Vive, Beatty, and Morgan [4] posits that companies are discovering new ways to create and sustain emotional connections with the brand.

Customer engagement is defined as behaviour-based relationship that extends beyond purchase and has a brand focus [5], [6]. Basically, customer engagement is a form of business communication that creates long term connection between a consumer and a business organization through various channels of correspondence. The channels can be offline, online or both. In the digital era, online channels have a global reach, which is ideal for hotel industry that eyes the global market. Hotel social media can be used to enhance customer engagement, supercharge brand awareness and boost revenue.

To contribute in this direction, this paper analyses the factors that influence the level of online hotel customer engagement in Twitter social media networking site. It focuses on three basic elements of the hotel's Twitter engagement strategy. One, when should hotel tweet and two, which content should be posted to trigger higher level of online Twitter engagement and three evaluate the level of Twitter online engagement. The research questions for the study are:

\footnotetext{
i. How are hotels timing their tweets?

ii. What content types are hotels using in their tweets?

iii. How engaging are hotel tweets?
} 


\author{
Vol. 8, Issue 4, April 2019
}

\title{
II.
}

\section{RELATED STUDIES}

The concept of brand image is not new, it has been in marketing and consumer research since the early 1950s. Aaker [7] argues that brand plays the important role of defining the product for consumers and differentiating the firm's offerings from the competitive offerings which is necessary for brand loyal customers. Brands is associated with an image in the consumer 's mind [8] and it comes as a result of experiential service. Branding is a set of activities associated with the process of giving a meaning to a specific company, products or services by creating and shaping a brand in consumers' minds. As mentioned earlier, brand building can be done either offline, online or as a combination of the two. Offline brand image has been researched on by several scholars [9]- [12] but little has been done on the online brand image [13]. These studies conclude that brand personality, brand attitude, brand concept, a customer 's previous experience and market communication are important elements that form brand image in the offline context. As for online brand image, Christodoulides [14] suggest that a "brand" is a universal concept regardless of setting (offline or online). This means both offline and online brand images are not different. Hotels need to present the same brand identity in both offline and online context, and customer 's perception of the brand (brand image) either in offline and online channels should be the identical.

Rowley [15] defines online branding as:

How online channels are used to support brands, which in essence are the sum of the characteristics of a product, service or organization as perceived and experienced by a user, customer or other stakeholder. From the definition, it is clear that online branding has three aspects. First it's about the channel, second it's about the attributes of a product or a service and finally it involves the perception and experience of the user. The definition can be conceptualized as having the identity (product/service attributes) and the image (perception/experience). The identity is defined by the organization but the image comes from the user. For effective hotel brand building, the hotels need the input of their customers. Social media presents a platform where hotels can engage their customers in the cocreation of the hotel brand. This study investigates how hotels are engaging their customers through Twitter in their brand building strategy.

\section{A. Social Media Branding}

According to SimilarWeb's [16] hotel traffic sources analysis, $47 \%$ of the hotel website traffic is direct, that is, a user types the Uniform Resource Locator (URL) of the hotel directly onto the browser address bar. This happen for hotel brands that are recognized by the consumers. One of the alternatives of creating hotel brand awareness among the consumers is for it to have an online presence. It's about putting the right content in the right place which can be done through hotel website, social media and content marketing. SimilarWeb further shows that $14 \%$ and $1 \%$ of the traffic originates form referrals and social media respectively. Referral still is attributed to recognized hotel brands.. Branding through social media as shown by SimilarWeb, is a source of traffic to hotel website which can be converted into a service for the hotel. These statistics demonstrates the important role played by social media in branding.

Yan [17] identified nine goals of social media in branding as creating sense of belonging to the organization, acceptance and communication of brand values and promoting the brand through engaging dialogue. The author argues that social media branding enhances competitive edge of the brand, helps in differentiation of the brand by highlighting the brand vision and act as a check on whether the brand is being properly communicated and understood by the consumers. The last three goals deal with the outcome of social media branding which are the creation of positive brand associations, perceived quality and greater awareness of the brand to the prospective customers.

As correctly argued by Neuhofer, Buhalis, and Ladkin [18], most travellers don't start making travel preparations by booking a hotel, but they use social media in pre-travel, during travel and after travel. Hotels need to use social media to the expectation of the majority of travellers who expect hospitality providers to engage with them before, during and after their trip to enhance their experience. So, it's important for hotels to create content that reaches guests at every "micro-moment" of the journey. The top five social media for hotels and resorts are Facebook, Instagram, Twitter, Pinterest, and TripAdvisor [19]. This study examined Twitter as a hotel online branding tool.

\section{B. Twitter}

Twitter is a digital and social media platform that consists of profiles and newsfeeds where users are able to post or share content (tweet) that is limited to 280 characters [20]. Tweeting is the process of putting post online for others to see in their newsfeeds. The use of Twitter Card enables tweets to contain links, photos, GIFs, or videos. Hotels can use Twitter in several ways such as raising awareness of the hotel brand, providing customer service, service recovery as well as a form of customer entertainment. Within hotel industry, service recovery process can be used to return aggrieved or dissatisfied customers to a state of satisfaction. Twitter is best used to update guests about things that are happening in real-time. For instance, the Sol Wave House Mallorca Hotel in Spain in 2012 created a Twitter-based community named \#SocialWave [19]. It was only available through the hotel's Wi-Fi, and guests got access to it by signing in using their Twitter account. The Twitter forum allowed the hotel community to share their experiences and 
guests get concierge services.

A research involving 20 of the largest hotel brands in the US found that, on average, hoteliers took more than seven hours to respond to customers on Twitter [21]. This is contrary to Twitter users' expectation of a tweet response within an hour, is an indication that hotels have not embraced the use of Twitter as a two-way communication channel. A study carried out by Twitter reveals that $71 \%$ of Twitter users expect a brand to respond within an hour of tweeting [22]. According to Rival IQ [23], the median online engagement rate of Twitter in hotel industry is $0.072 \%$. The same study shows that the median post per day for Twitter in hotel industry is 0.6 with all industries having a median of 1.12 . Twitter social media platform allows users to include attachments in their tweets. The use of attachments enriches the content with multimedia capabilities. Videos stands out as the best channels for user engagement. According to Twitter 's own research, tweets with video generate nine times more engagement than basic text updates [24]. With regard to online branding, Twitter 's own research asserts that users who view videos on Twitter are 50\% more likely to be aware of an advertiser 's brand [25]. Twitter further posits that users who view videos on Twitter feel $14 \%$ more favourable about the brand [24]. The above research findings show that Twitter videos enhances brand awareness.

\section{Twitter Post Scheduling}

Knowing the best times to tweet for maximum engagement is a boost for online branding. The practice of tweeting when their consumers are listening can have a positive impact on hotel brand. This makes sense with regards to reaching a good number of the consumers. The Twitter post timing can be done in terms of the days of the week and time of the day. For hotel industry that focuses on customers from different time zones, it becomes a challenge to have an optimal schedule that works for all regions. Moreover, there are country specific engaging behaviour of audiences. This makes post scheduling a difficult question for hotels to handle and therefore it should be evaluated to a greater depth. Previous studies of temporal interaction patterns have shown that most of the user activities on social network sites are undertaken during workdays [26]. Social media users have been found to engage less during the morning and early afternoon, with increased engagement toward the evening, reaching a steady, high level during the night [26]. A study carried between October 2010 and March 2015 with 4.8 million tweets segmented by ten major global time zones reveals that the most popular time to tweet is noon to 1:00 p.m. [27]. The same research shows that the highest volume of tweets occurs between 11:00 a.m. and 1:00 p.m., peaking between noon and 1:00 p.m. The fewest tweets are sent between 3:00 a.m. and 4:00 a.m.

According to Patel [28], engagement is at the highest during Thursday and Friday, whereas Monday, Tuesday, and Wednesday faces a $3.3 \%$ decrease in engagement. This author suggests that hotels should post at 1 pm if they are looking for a bigger number of shares and $3.00 \mathrm{p} . \mathrm{m}$. if they want more clicks. Golan [29] posits that the best day(s) to post are Wednesday, Thursday and Friday. The author explains that at this time, the week is almost over and everyone is feeling pretty good. It is argued that Fridays have the highest happiness index of any day of the week at 10\% [28]. Hence, if a post is created in the period when social network site fans are more active, there is a greater possibility for the brand post to be seen on the wall, resulting in greater potential engagement.

\section{Twitter Content Type}

The number of followers in Twitter is influenced by the content type. The more informative and entertaining the content are, the higher the chances of growing the number of Twitter followers. It's the content that also convey the brand identity to the consumers. It is therefore important for hotels to have connection between Twitter content and their brand. Using appropriate Twitter content will help them connect with their target audience, being more strategic with their effort will go a great length at building their brand. Text in Twitter can not only be used for status (pure text) but can also be used together with other content types. Written text is ideal for creating relationship between brand and consumer, showing experiences and expertise, build-in consumer trust and sharing customer testimonials [30]. Another type of static content that can be used in Twitter is infographics (information graphic). Research has it that infographics aids in remembering and understanding content quickly [30].

This is partly because visually engaging content is more attractive and if well designed, it quickly piques interest before information is processed [31]. Graphics are best for attracting attention and interest to a brand, creating memorable content, making persuasive argument and presenting complex data and ideas [30]. Tweets with images receive $150 \%$ more retweets than tweets without images [32]. The use of Twitter Card allows tweets to have videos. According to Bernazzani [30], videos are ideal for contents like sharing brand stories, forming emotional connection between a brand and its consumers and showing how to execute a task. Studies have shown that people can recall about $65 \%$ of visual content three days later, compared to only $10 \%$ for written content [33]. Several researchers have in the past explored the use of videos in Twitter posts. In a 2018 Hub Spot survey, 54\% of consumers wanted to see more video content from a brand or business they support [34]. According to Twitter itself, $90 \%$ of all video plays on Twitter take place on mobile devices [35]. It is important for hotels to factor in the aspect of infographics in their branding strategy for optimal engagement with their consumers. 


\section{E. Twitter Engagement}

There is no doubt about the content being the king, but online engagement rules. There will be no point of creating Twitter content if no one engages with it. This will be like a hotel having a conversation with itself and its brand will be unknown. Hotels have an opportunity of building awareness for their brand on Twitter by engaging and interacting with their consumers. This is why the number one priority for hotels using Twitter for branding should be to get consumers engaged with their brand content. Engagement on Twitter accounts for the public ways in which the social audience can interact with the hotel posts or make them show up in their Newsfeeds and those of their social networks. It consists of likes, comments, retweets, reactions and conversations with a post in Twitter. Engagement measures people's interactions with the content and promotion of the content to their circles of influence. Engagement metric not only reveals the posted content's ability to capture user attention and ability to compel user action but also the number of people who were served by the post and the brand visibility.

In the recent past studies have put more focus on customer engagement. Hoffman and Fodor [36] argued that increasing the levels of customer engagement enhances the customer retention rate and leads to better business performance. It is further argued that higher customer retention rates can result in increased profit for an organization [37]. Simply Measured [38] identifies the brand's ability to capture users' attention, create a connection with its content and showing how many people see the brand's posts as the three vital things that engagement with the brand's posts reflects. It is through customer engagement that a hotel is able to learn about their audience behaviour and preferences, like which types of content they are interested in and whether certain segments of their audience interact more or less with content that is specifically tailored to them. In this study, Twitter engagement is used as a means of achieving two-way communication between the hotel and their consumers for branding purpose. Researchers in the recent past have also operationalized social media engagement to represent two-way communication [39].

\section{METHODS}

This study employed quantitative research approach that used media content analysis. Social media analytics tools were used to monitor, collect, analyse, summarize and visualize Twitter data from star rated hotels in Kenya. Zeng, Chen, Lush, et al. [40] defines social media analytics as the process of creating and evaluating informatics tools and frameworks to gather, monitor, analyse, summarize, and visualize social media data in order to facilitate conversations and interactions with the aim of extracting useful patterns and intelligence. In the recent past, a number of researchers have employed media content analysis in studies in differrent disciplines such as websites [41]- [45], social networking sites [46]- [49], E-commerce [50], [51] as well as in gaming and simulation [52], [53].

The target population for the study were Kenyan star rated hotels with websites. The details of star rated hotels were obtained from Tourism Regulatory Authority (TRA) through Kenya Gazette Notices Vol. CXVII No. 94 and Vol CXVIII No. 28 of 2016 [54]. At the time of research data collection, three star and above rated hotels in Kenya were 123 [54]. Where there were several hotels belonging to one hotel chain, only one hotel website was used. Simple random sampling was used for selection of hotel websites for the sample. Using Yamane formula [55], 64 hotel websites were identified for the study. Within the 64 hotels, 35 hotels that had their Twitter accounts connected to their websites were sampled. Twitter account is said to be connected if it has a link from the hotel website to the Twitter Page.

The research data was collected over a period of 12 weeks spread over one year. This was done to take care of seasonal variations in terms of hotel bookings. Data was collected over four weeks period both in the months of September and December of the year 2017 and another four weeks the month of April 2018. This study used Fanpage Karma, a premium social analytics tool. It is in an online tool for social media monitoring and analytics [56]. Fanpage Karma provides valuable and deep insights on performance and posting strategies of social media profiles such as Instagram, Facebook, YouTube, Twitter, Google Plus and LinkedIn. Fanpage Karma has been used in several studies on social media [57]- [59].

\section{RESULTS AND DISCUSSION}

Research question one of the study inquired as to "how are hotels timing their tweets?" To answer this question, data on the tweets timing in terms of the days of the week and time of the day was collected. The results reveals that the highest number of posts are done on a Friday with an average of $74(18.5 \%)$ posts. The least posts happen on a Sunday with an average of $32(5 \%)$ posts. Figure 1 shows the hotel Twitter posting pattern by the days of the week. 
Vol. 8, Issue 4, April 2019

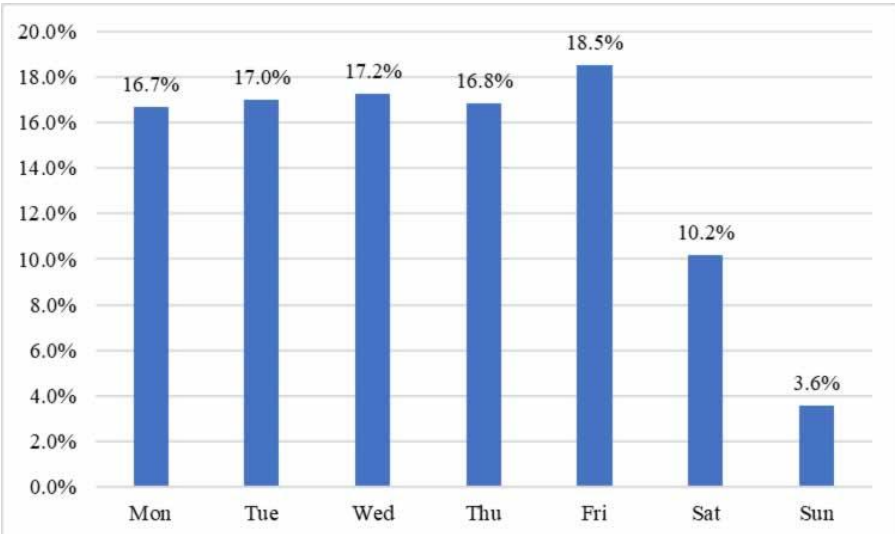

Fig. 1. Twitter posting frequency by days of the week.

The research data was also analysed in terms of reactions a post generated in the days of the week. The results indicate that the highest number of reactions are recorded on a Wednesday (18\%) followed by Thursday. Tuesday and Saturday both are recording $15 \%$ of the reactions. The least number of reactions are recorded on a Monday (10\%). Figure 2 exhibits the frequency of hotel tweets reactions by days of the week.

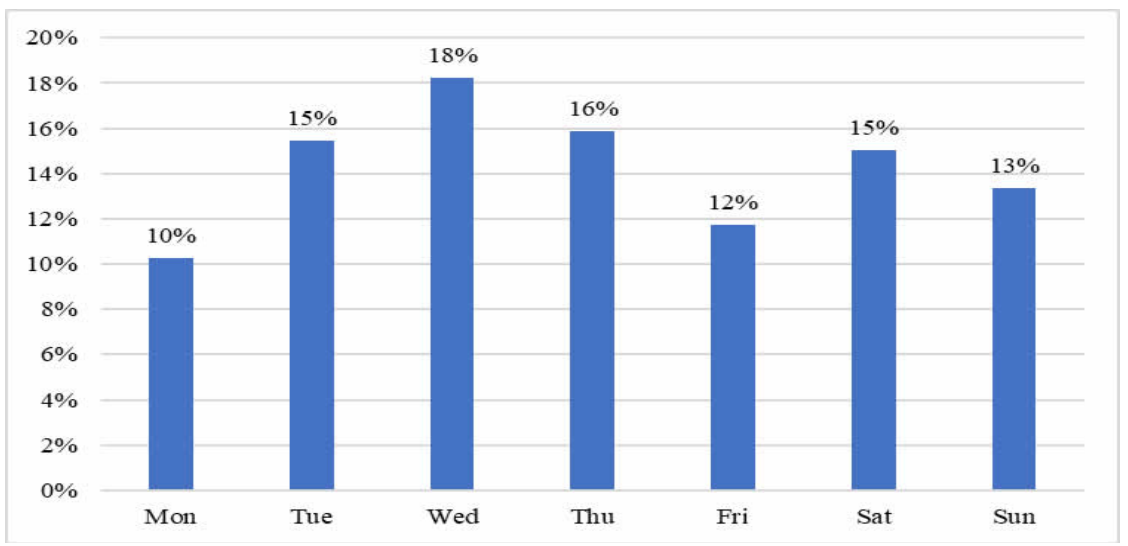

Fig. 2. Frequency of Twitter Reaction on Posts by Days of the Week

With respect to the time of the day, the results indicate that the highest number of Twitter post are done between 8.00 a.m. and noon with the highest recorded on Saturdays. The least number of posts (1\%) are done in the morning between 1.00 a.m. and 4.00 a.m. throughout the week with exceptions of Thursday and Friday that records $3 \%$ of the posts being posted. Without considering the day of the week, the results indicate that the highest number of tweets are done between 8.00 a.m. and noon. The least number of tweets occur between 1.00 a.m. and 4.00 a.m. in the morning. Figure 3 exhibits more details on the Twitter posting by time of the day.

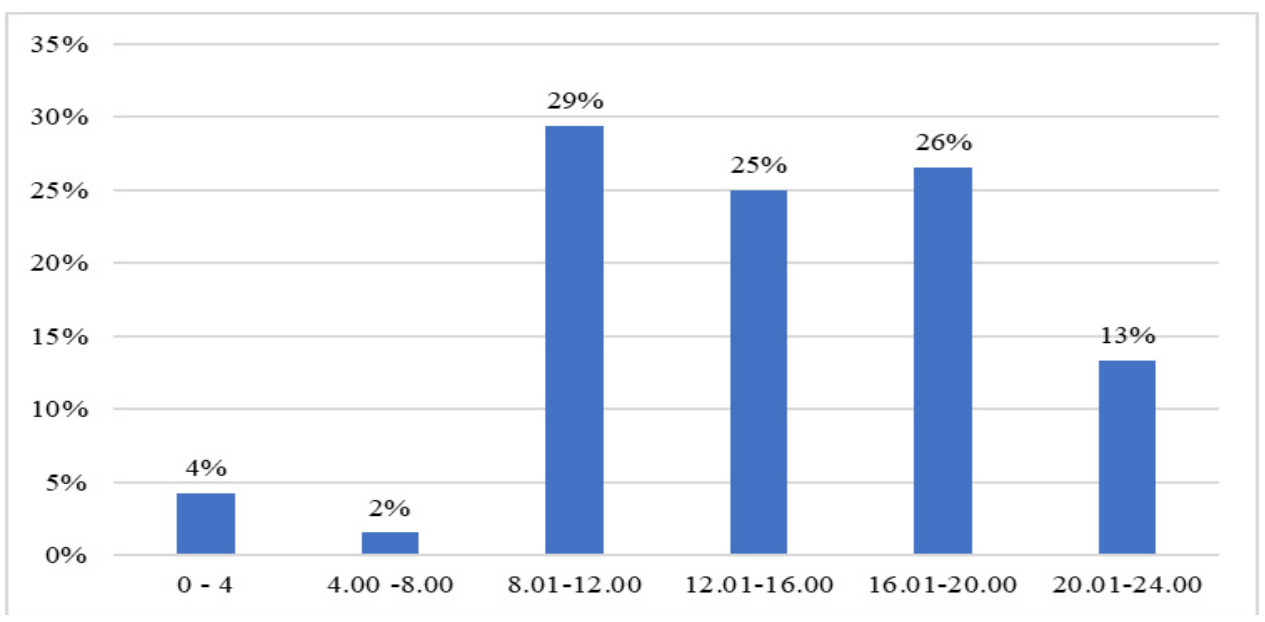

Fig. 3. Twitter Posts by Time of the Day. 
The analysis of Twitter posts reactions by time and days of the week reveals that the highest number of reactions (78\%) are recorded on Saturday morning between 8.00 a.m. and noon. There are no reactions observed on Monday, Wednesday and Friday morning between one and four in the morning. In terms of time of the day without reference to the day of the week, the results indicate that the highest reactions are recorded between 8.00 a.m. and noon. The least reactions are experienced $4.00 \mathrm{a} . \mathrm{m}$. and 8.00 a.m. Figure 4 exhibits more details on the tweets reactions by time of the day.

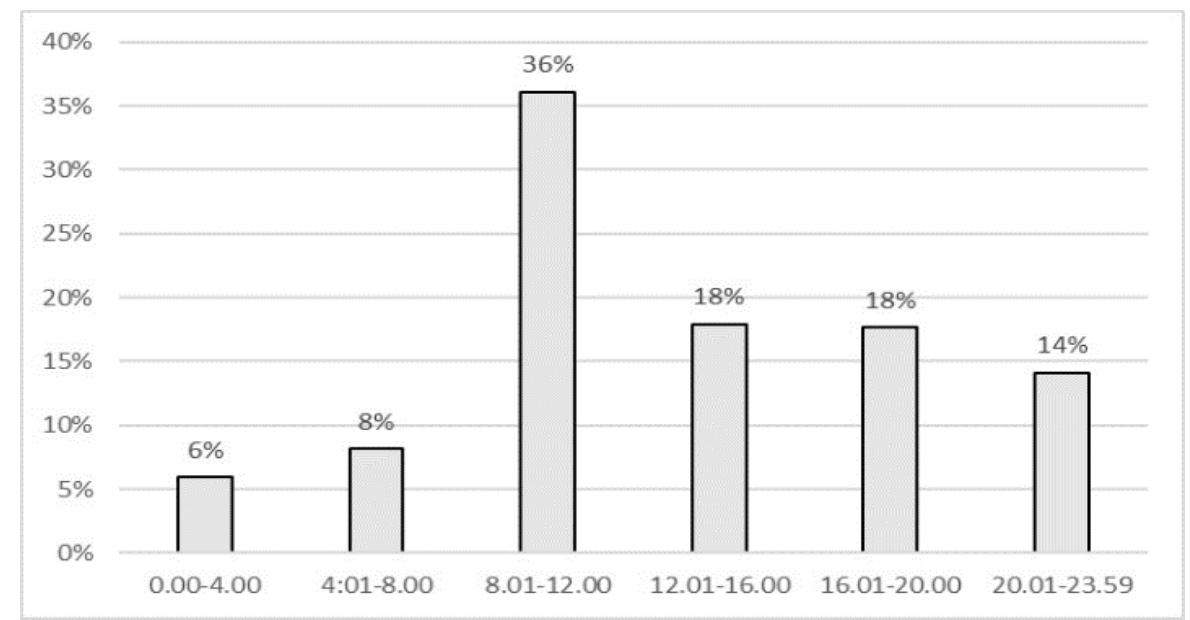

Fig. 4. Twitter Average Reactions by Time of the Days

Knowing the best time to post in Twitter enhances online engagement with hotel Twitter feeds. Using guess work with respect to hotel Twitter timing may not generate maximum reaction. It is important for hotels to understand the time of the day and day of the week that their consumers are more likely to use Twitter platform. The results show that hotels Twitter posting is evenly spread over the workweek having a peak on Friday. It's lowest on Monday but gradually increase with a slight drop on Thursday. This can be attributed to hotel Twitter administrators being at work during the weekdays. It is interesting to note that most of the posting are done in the morning between 8.00 a.m. and noon. This is the time hotel employees report to work and being fresh they deliver more tweets at this time. The least Twitter postings are done over the weekends (14\%). This can be explained by the fact that over the weekends some hotel employees take weekend break and the hotel is working with lean staff.

From the results it can be seen that reaction rates are worst on Mondays, which makes sense. Monday mornings are the most critical time of the workweeks, people set the stage for the day and week ahead. People update their to-do list and goals. They cannot afford time to engage in Twitter. The reactions increase on Tuesday as a rebound, and reach the peak on Wednesday. There is a drop on Thursday, because people tend to go out or spend time with families on Friday. Over the weekend the reactions drop a bit. This is so because some people unplug from the day-to-day routine and get a chance to think more deeply about their work, career and make time for family and friends. From the results, the timing for peak user hours vary from day to day of the week. There are some general consistencies, though. For one thing, the peak reactions are generated in the morning between $8.00 \mathrm{a} . \mathrm{m}$. and 12.00 noon. There are little reactions between $1.00 \mathrm{a} . \mathrm{m}$. and $4.00 \mathrm{a} . \mathrm{m}$. as people are asleep. Then between $4.00 \mathrm{a} . \mathrm{m}$. and $8.00 \mathrm{a} . \mathrm{m}$. the reactions increase marginally. This can be attributed to the to and from work commutes when people get time for Twitter usage. People check before work and after, to see what they have missed. Additionally, in the evenings, reactions go up which can be explained by commuting to and from work. They get some time to check on tweets. Due to the nature of the hotel industry and varying time zones of their potential customers, it is not easy to say which time is the best for Twitter posting. However, the number of reactions a post generates can be used as an indicator of the time hotel customers are online and engages with Twitter. But this should not be taken as the actual indicator since the reactions are also influenced by the tweet content.

\section{A. Twitter Content Type}

Research question two of the study inquired as to "what content types are hotels using in their tweets?". To answer this question, data on Twitter content types (new content, replies to others and re-shared), type of post (status, videos, links and pictures) and attachment type (text, pictures, links videos and links \& pictures) was collected and analysed.

With respect to the type of content the results show that $45 \%$ of the tweets are of new content, $34 \%$ are replies to tweets and $21 \%$ are re-shared content. Figure 5 exhibits the content types used in tweets. 
Vol. 8, Issue 4, April 2019

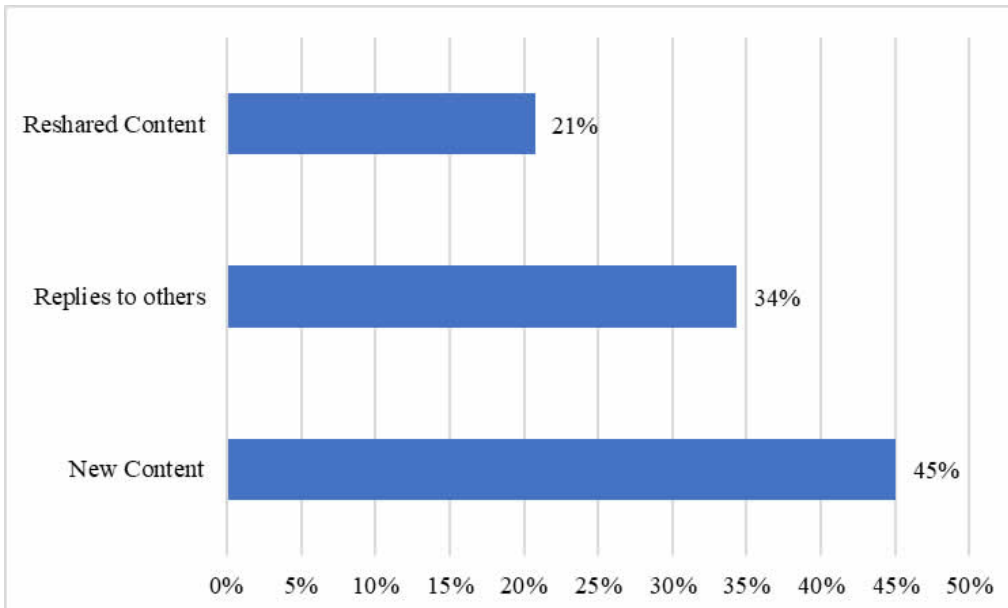

Fig. 5. Types of Tweet Posts

For the Twitter post type the results indicate that the most commonly used media type in hotel tweets are pictures $(83 \%)$ followed by attachments and videos each with $8 \%$ share of the posts. The least used is status (1\%). Figure 6 shows how the various types of media are used in hotel Twitter posts.

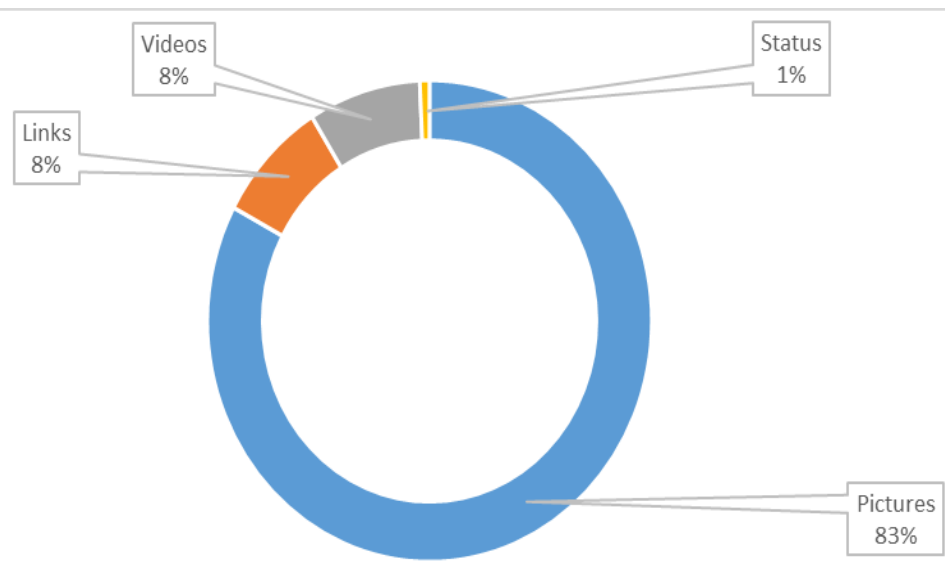

Fig. 6. Twitter Types of Posts.

In the tweets attachment type, the results reveals that the most commonly used attachment type are pictures (39\%) followed by text (30\%). The least used attachment type is video (6\%). Figure 7 exhibits the level of usage of various types of attachments on Twitter posts.

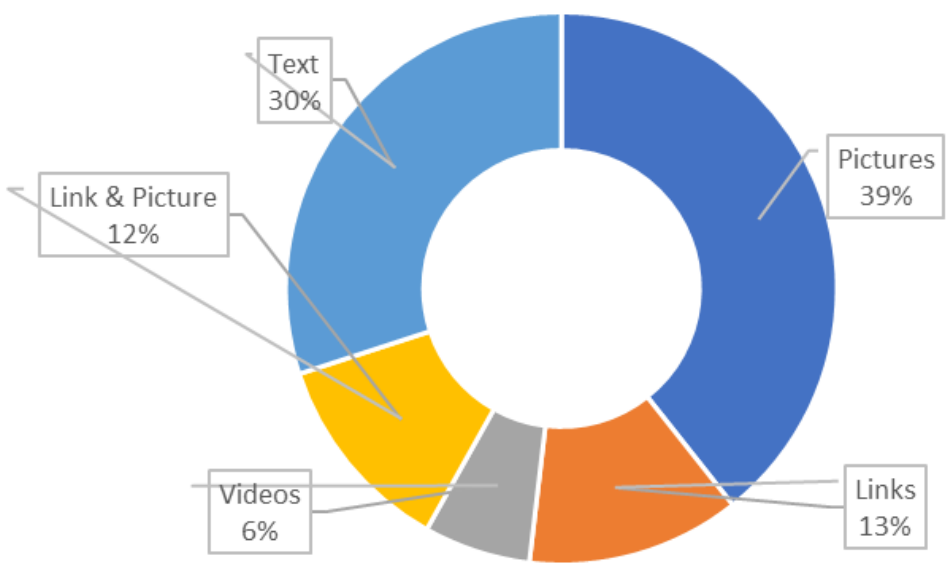

Fig. 7. Type of Attachment used in Twitter Posts 
The hotel feed's use of Twitter's structural features suggests that the hotels do consider the strategic and tactical potential of Twitter's potential effect on their users. The usage of Twitter video by Kenyan hotel is low which contributes to lower Twitter engagement rate and does not promote useful information to the users. That means the awareness and sentiment of the hotel brand is not effectively managed. The use of Twitter videos enhances brand awareness and sentiment which contributes to long term relationship building with the users. The positive Twitter followers' growth rate $(0.25 \%)$ observed in the sampled hotel Twitter accounts indicate that the hotels are gaining new followers. Users are retained by regular posting of content. The results indicate that close to half of the tweets (45\%) are new content with about one-third being replies to other tweets. The new content is important as they convey information on the current activities in the hotel. Hotel reputation can be enhanced if the focus is on creating useful content related to their offerings that their customers will share owing to its usefullness. Specific content is powerful, and has the potential of enhancing the hotel's brand equity. The replies to other tweets form the Twitter conversations with customers.

About one fifth of the content is re-shared content. Re- sharing content has the potential of building trust in the hotel. By focusing on showing the hotel through guests' eyes, the hotel can win trust of their consumers. This can be done by re-sharing visual of hotel offerings that were taken by their customers, other travellers, and photographers.

The research data shows that Kenya hotels post content regularly (media tweets per day is 0.63 ) which can encourage users to engage with the hotels' feeds. The posting frequency also resonates well with the users. The results show that highest number of reactions are observed on Saturdays and the highest number of posting is done on a Friday. This works well since user are free on Saturdays and find content that was posted the previous day to engage with. In terms of time of the day, the highest number of posts are also done on Saturday morning when the highest number of users are online.

In conclusion, hotels need to regularly post a steady stream of fresh content to their Twitter fans. They should employ the use of appropriate multimedia. The aspect of quantity and quality should also be considered in the tweets.

\section{B. Engagement}

Research question three inquired as to "what is the level of online engagement are hotel tweets generating?". The degree of online Twitter engagement was measured through metrics like weekly growth rate, number of tweets per day, numbers of likes, number of comments, rate of engagement, post interaction and conversations. The results reveal that the median hotel daily tweets is 0.63 , with weekly average engagement rate of $0.05 \%$ and average conversation rate of $1.62 \%$. Table 1 exhibits the details of Twitter Key Performance Indicators.

Table 1:Twitter Key Performance Indicators

\begin{tabular}{|l|l|l|l|l|l|}
\hline & $\begin{array}{l}\text { Weekly } \\
\text { Growth }\end{array}$ & $\begin{array}{l}\text { Tweets } \\
\text { Per day }\end{array}$ & $\begin{array}{l}\text { Average } \\
\text { Retweets }\end{array}$ & $\begin{array}{l}\text { Engagement } \\
\text { Rate }\end{array}$ & Conversations \\
\hline Mean & $0.43 \%$ & 0.734 & 68 & $0.072 \%$ & $4.86 \%$ \\
\hline Median & $0.25 \%$ & 0.634 & 15 & $0.049 \%$ & $1.62 \%$ \\
\hline Min & $-0.48 \%$ & 0.03 & 60 & $0.000 \%$ & $0.00 \%$ \\
\hline Max & $7.15 \%$ & 5.375 & 1095 & $0.822 \%$ & $62.61 \%$ \\
\hline
\end{tabular}

It is essential in the hospitality industry to respond to messages within a short time. These responses in Twitter constitute conversations. The research data shows that median conversation is $1.62 \%$. This is an indicator that there is dialogue between the hotels and their customers. Conversation with consumers is very important in hotel industry. Hotels can use conversations for directing the customers to the correct sources as well as in offering customer services. Conversation can also be used to manage hotel service recovery and addressing customer complains. These activities can take place through Twitter conversations. This research shows that the hotels are starting to embrace conversations in their tweets, which is good for addressing the discussed issues. The results indicate that the Kenyan hotels median daily tweeting frequency (0.63) is at per with the hotel industry 's global median of $0.6 \%$. This can be interpreted that the hotels are adequately putting their consumers in the know of day to day happenings in their facilities. Keeping the consumers in the know has the potential of provoking the customers' interest and excitement. This is useful for customers who are just beginning to research their next trip, and it provides useful information for those who are currently staying at the hotel. Optimal frequency of tweeting can increase the hotel brand equity.

The growth of active followers is a prerequisite for Twitter engagement. Hotels need active online customers to engage with. This can be done by creating content that target the needs and concerns of the hotel customers. The research data results further show a positive hotel Twitter followers' growth rate. This is a good sign and hotels need to find out all of the different questions or problems their target audiences have and create detailed content solving those problems. This will help to build their trust in the hotel which will increase the hotel's brand equity. 
Retweets and likes were used as proxies for the user interaction principle. This study assumed that liking and/or retweeting the tweet demonstrated that hotel Twitter followers were interacting with the hotel Twitter feed. Liking the tweet can be considered as interacting with the feed itself. Hotel managers are able to see the likes and judge Twitter feeds. The media engagement rate in the current study is lower than the global online engagement rate of hotel industry of $0.072 \%$ discussed in section B.

Engagement is about what customers want or like. Human brains process all decisions as potential rewards driven by two systems, that is what they want and what they like. As earlier discussed, infographics are easier to process than written text. The study results indicate low usage of videos; this could be the reason why the engagement rate for Kenyan hotels in below the global median $(0.072 \%)$. The use of multimedia can also have influence on the rate of engagement. People like variety, the use of different media types can result in higher engagement rate. Hoteliers need to put more emphasis on the use of multimedia in their tweets.

The results showed that link posts and videos were the most engaging post type, receiving each 3.4 reactions per post on average compared to 1.9 and 1.0 reaction per post for status and pictures respectively. This suggests that hotel Twitter fans are more likely to see video and link posts as novel, interesting, and worthy of reacting to, which is in line with current industry predictions about the value of video for any content provider [60]. However, only $9 \%$ and $8 \%$ of all posts coded were videos and links respectively suggesting that hotels in Kenya are trailing behind conventional branding. Conversely, pictures and status (text-only) posts received fewer reactions than photo and link posts, implying that these posts are generally not seen as engaging, regardless of the content. The results suggest that status in particular do not promote engagement, especially when it seems that status are generally reach fewest number of people of all types of posts.

\section{CONCLUSION}

Hotel branding is the process of creating a memorable image of it with guests and fans. Building hotel brand identity helps show trust, expertise and professionalism. The hotel managers shape the brand identity while the guests shape the brand image. Twitter is one of the social media networks, through which hotels can get the voice of their customers to help in building a strong hotel brand through co-creation within a short period. Twitter based hotel branding can be effectively and efficiently achieved through getting more users to engage with the hotel tweets and branded content. Writing tweets and publishing them at the right time when the hotel customer is active is necessary to achieve the best results. The tweets should not only have specific content but must also be in media types that generate more engagements from the users.

This study analysed hotel Twitter engagement through timing of the posts and the content media type. The results indicate that posting is spread evenly over workweek with the highest number occurring on Friday. Weekends record reduced posting with Sunday having the least. In terms of time of the day, the highest number of posting are done between eight in the morning and midday. The least number posts are done between four and eight in the morning. The highest number of reactions are observed on Wednesday and the least on Monday. With respect to time of the day, the highest number of reactions are recorded between eight in the morning and midday. This is what objective one sought to achieve. In terms of Twitter post content, close to half of the content are made up of new content with one third as replies to others and the rest being re-shared content. Pictures constitute more than $80 \%$ of the post types with status being the lowest at $1 \%$. Videos and links are not commonly used. The Twitter post attachments are majorly made up of pictures with little use of videos. These are the results for objective two.

The results indicate that though the posting frequency of the sampled hotels are at per with the global industrial median, the engagement rate is lower. This can be attributed to the low use of more engaging media type like videos and info graphics. These results are the outcome of objective three. Clearly, there is need for hotels to take their online reputation seriously. Hotel being a people's business, what attracts them is reputation. Hotel guests trust electronic word of mouth more and it will be of benefit for hotels to keep track of their customers' sentiments and set objectives of what they want their guests to say about your hotel once they leave. The findings of this research have practical and theoretical implications. On the practical side, this research sheds light on how Twitter is utilized by hotels for branding purposes, and creates recommendations on how hotels can widen the broadcasting of messages and reach target audiences. On the theoretical side, this research enriches the literature in the application of Twitter in hotel industry. This study did not dig into the tweet messages and that is the limitation of the study. It will be interesting to explore the effect of user sentiments on Twitter engagement. This study therefore suggests that future research follows this direction. 


\title{
International Journal of Advanced Research in Computer and Communication Engineering
}

\author{
Vol. 8, Issue 4, April 2019
}

\section{REFERENCES}

[1]. N. Zmuda. (Dec. 1, 2017). The new consumer behaviour that defined Google's year in search, [Online]. Available: https://www.think with google.com/consumer-insights/marketing -trends-year-in-search-2017/

[2]. Salesforce, "State of the connected customer insights", Salesforce, 2016.

[3]. B. Solis, "Digital transformation of the guest experience", Sabre, 2018.

[4]. S. D. Vivek, S. E. Beatty, and R. M. Morgan, "Customer engagement: Exploring customer relationships beyond purchase", Journal of marketing theory and practice, vol. 20, no. 2, pp. 122-146, 2012

[5]. J. Van Doorn, K. N. Lemon, V. Mittal, S. Nass, D. Pick, P. Pirner, and P. C. Verhoef, "Customer engage- ment behaviour: Theoretical foundations and research directions", Journal of service research, vol. 13, no. 3, pp. 253-266, 2010.

[6]. R. Dolan, J. Conduit, J. Fahy, and S. Goodman, "Face- book for wine brands: An analysis of strategies for facebook posts and user engagement actions", in 9th Academy of Wine Business Research Conference, vol. 17,016.

[7]. D. A. Aaker, "Managing brand equity: Capitalizing on the value of a brand name, New York", Google Scholar, 1991.

[8]. K. L. Keller, "Conceptualizing, measuring, and man- aging customer-based brand equity", the Journal of Marketing, pp. 1-22, 1993.

[9]. W.-S. Kwon and S. J. Lennon, "Reciprocal effects be- tween multichannel retailers' offline and online brand images", Journal of Retailing, vol. 85 , no. 3, pp. 376-390, 2009 .

[10]. K. Hongyoun Hahn and J. Kim, "The effect of offline brand trust and perceived internet confidence on online shopping intention in the integrated multi-channel context”, International Journal of Retail \& Distribution Management, vol. 37, no. 2, pp. 126-141, 2009.

[11]. P. Kotler, Marketing management: Analysis planning implementation and control, 1994.

[12]. C. W. Park, B. J. Jaworski, and D. J. Maclnnis, "Strategic brand concept-image management", The Journal of Marketing, pp. 135-145, 1986.

[13]. D. Nunthapirat, "Strategy of enhancing online brand image for the hotel business", Executive Journal, vol. 35, no. 1, pp. 53-63, 2015.

[14]. G. Christo Doulides, "Breaking free from the industrial age paradigm of branding", Journal of Brand Management, vol. 15, no. 4, pp. 291-293, 2008.

[15]. J. Rowley, "Online branding strategies of uk fashion retailers", Internet Research, vol. 19, no. 3, pp. 348-369, 2009.

[16]. SimilarWeb. (Jan. 21, 2019). Hotels.com Traffic Sources, [Online]. Available: https://www.similarweb.com/website/hotels.com\#overview

[17]. J. Yan, "Social media in branding: Fulfilling a need", Journal of brand management, vol. 18, no. 9, pp. 688-696, 2011.

[18]. B. Neuhofer, D. Buhalis, and A. Ladkin, "A typology of technology-enhanced tourism experiences", International Journal of Tourism Research, vol. 16 , no. 4 , pp. $340-350,2014$

[19]. N. Severt. (Apr. 27, 2018). 8 hotel social media marketing strategies and tips, [Online]. Available: https://unamo.com/blog/social/8-hotelsocial-media-marketing-strategies-and-tips

[20]. G. Pinegar. (Jul. 18, 2018). What is twitter: A beginner's guide, [Online]. Available: https://learn.g2crowd.com/what-is-twitter

[21]. M. gallucci. (Jun. 25, 2014). Hotels lag in social media customer service, [Online]. Available: http://www.hotelnewsnow.com/Articles /23034/ Hotels-lag-in-social-media-customer-service

[22]. S. Picazo. (Sep. 19, 2018). Customer service on twitter and the impact on brands, [Online]. Available: https://blog.twitter.com/marketing/en_gb/a /en-gb/2016/customer-service-on-twitter-and-the-impact-on-brands.html

[23]. Rival IQ, "2018 social media benchmark report: Industry benchmarks across the most important social media metrics", Rival IQ, 2018.

[24]. A. Hutchinson. (Jul. 6, 2017). Using twitter video (from twitter), [Online]. Available: https://www.socialmediatoday.com/social-business/ 3reasons-why-you-should-be-using-twitter-video-twitter

[25]. IPG Media Lab, Beyond completion rates: How social video works, 2017.

[26]. TrackMaven, "The best times to post on social media", TrackMaven, 2016.

[27]. K. Lee. (Dec. 1, 2016). The biggest social media science study: What 4.8 million tweets say about the best time to tweet, [Online]. Available: https://buffer.com/resources/best-time-to-tweet-research\#free-course

[28]. N. Patel. (Jan. 2, 2018). What are the best times to post on social media? [Online]. Available: https://www.quicksprout.com/best-times-topost-on-social-media/

[29]. M. Gollin. (Jul. 4, 2018). What are the best times to post on social media in 2018? [Online]. Available: https://www.falcon.io/insightshub/topics/ social-media-management/best-time-to-post-on-social-media-2018/\#/G EN

[30]. S. Bernazzani. (Jul. 28, 2017). How the brain processes different types of content? [Online]. Available: https://blog.hubspot.com/marketing /brain-processes-different-kinds-of-content

[31]. G. McCracken, O. Oullier, and T. Zoëga, "The science of engagement an exploration into the true nature of engagement-what it means and what causes it", Grounded in science, not fiction, 2014.

[32]. B. B. Cooper. (Apr. 27, 2016). How twitter 's expanded images increase clicks, retweets and favourites, [On- line]. Available: https://buffer.com/ resources/the-power-of-twitters-new-expanded-images-and-how-to-make-the-most-of-it

[33]. J. Medina, Brain rules: 12 principles for surviving and thriving at work, home, and school. ReadHowYouWant. com, 2011.

[34]. M. An. (Dec. 14, 2018). Content trends: Preferences emerge along generational fault lines, [Online]. Avail- able: https://blog.hubspot.com/ news-trends/content-trends-references?_ga =2.263846414.329169058. 1555392566-1665843349.1530356058

[35]. M.Window. (Dec. 8, 2016). How to incorporate video into your content strategy, [Online]. Available: https://business.twitter.com/en/blog/ how -to-video-content-strategy.html

[36]. D. L. Hoffman and M. Fodor, "Can you measure the roi of your social media marketing?", MIT Sloan Management Review, vol. 52, no. 1, p. $41,2010$.

[37]. F. F. Reichheld and J. W. Sasser, "Zero defections: Quality comes to services.”, and Harvard business review, vol. 68, no. 5, pp. 105-111, 1990.

[38]. Simply Measured, the complete guide to facebook analytics: How to analyze the metrics that matter, 2014.

[39]. W. Shin, A. Pang, and H. J. Kim, "Building relation- ships through integrated online media: Global organizations' use of brand web sites, Facebook, and twitter", Journal of Business and Technical Communication, vol. 29, no. 2, pp. 184-220, 2015.

[40]. D. Zeng, H. Chen, R. Lusch, \& S.-H. Li, "Social media analytics and intelligence", IEEE Intelligent Systems, vol. 25, no. 6, pp. 13-16, 2010.

[41]. S. Livingston and W. L. Bennett, "Gatekeeping, indexing, and live-event news: Is technology altering the construction of news?", Political Communication, vol. 20, no. 4, pp. 363-380, 2003.

[42]. M. A. Xenos and K. A. Foot, "Politics as usual, or politics unusual? position taking and dialogue on campaign websites in the 2002 us elections", Journal of Communication, vol. 55, no. 1, pp. 169-185, 2005.

[43]. P. Samuelson, "Mapping the digital public domain: Threats and opportunities", Law \& Contemp. Probs., vol. 66, p. 147, 2003.

[44]. H.-J. Paek, J. Yu, and B. J. Bae, "Is on-line health promotion culture-bound? Cultural characteristics manifested in us and south korean antismoking web sites", Journal of Advertising, vol. 38, no. 1, pp. 35-48, 2009.

[45]. J. N. Druckman, M. J. Kifer, and M. Parkin, "The technological development of congressional candidate web sites: How and why candidates use web innovations", Social Science Computer Review, vol. 25, no. 4, pp. 425-442, 2007. 
[46]. P. Owoche, S. Mbugua, and A. Ikoha, "Hotel branding using facebook and dialogic principles of internet communication", International Journal of Advanced Re- search in Computer Engineering and Technology, vol. 8, no. 2, pp. 38-46, 2019.

[47]. L. Wallace, J. Wilson, and K. Mooch, "Sporting Facebook: A content analysis of ncaa organizational sport pages and big 12 conference athletic department pages", International Journal of Sport Communication, vol. 4, no. 4, pp. 422-444, 2011.

[48]. T. McCorkindale and M. Morgoch, "An analysis of the mobile readiness and dialogic principles on for- tune 500 mobile websites", Public Relations Review, vol. 39, no. 3, pp. 193-197, 2013.

[49]. J. K. Woolley, A. M. Limperos, and M. B. Oliver, "The 2008 presidential election, 2.0: A content analysis of user-generated political Facebook groups", Mass Communication and Society, vol. 13, no. 5, pp. 631-652, 2010.

[50]. C. J. Auster and C. S. Mansbach, "The gender marketing of toys: An analysis of colour and type of toy on the Disney store website", Sex Roles, vol. 67 , no. 7-8, pp. 375-388, 2012.

[51]. K. Y. Peterkin, "Online travel agencies as a source of hotel information: A content analysis", PhD the- sis, Master Thesis of European Master in Tourism Management, 2014.

[52]. M. C. Burgess, K. E. Dill, S. P. Stermer, S. R. Burgess, and B. P. Brown, "Playing with prejudice: The prevalence and consequences of racial stereotypes in video games", Media Psychology, vol. 14, no. 3, pp. 289-311, 2011.

[53]. E. Downs and S. L. Smith, "Keeping abreast of hyper- sexuality: A video game character content analysis", Sex roles, vol. 62, no. 11-12, pp. $721-733,2010$

[54]. TRA. (2017). Classified Tourism Enterprises register of classified establishments for the period 2015-2018 in Kenya by TRA classification regions, [On- line]. Availablehttps://www.tourismauthority.go.ke/ index.php/resource-centre/downloads/category/12-classified-tourismenterprises (visited on 06/15/2017).

[55]. G. D. Israel, "Determining sample size", 1992

[56]. Fanpage Karma. (2017). Fanpage karma what is fan- page karma? [Online]. Available: https://www.fanpagekarma.com/about(visited on 06/15/2018).

[57]. S. Jayasingh and R. Venkatesh, "Customer engagement factors in Facebook brand pages", Asian Social Science, vol. 11, no. 26 , p. 19, 2015.

[58]. J. Tarai, R. Kant, G. Finau, and J. Titifanue, "Political social media campaigning in Fiji’s 2014 elections", 2015.

[59]. T. Wozniak, B. Stangl, R. Schegg, and A. Liebrich, “The return on tourism organizations' social media investments: Preliminary evidence from Belgium, France, and Switzerland”, Information Technology \& Tourism, vol. 17, no. 1, pp. 75-100, 2017.

[60]. C. Trimble. (Jul. 17, 2015). Why online video is the future of content marketing2015, [Online].Available: https://www.theguardian.com/ small business-network/2014/jan/14/video-content-marketing-media-online 